\title{
Development of Iranian Computer Attitude Scale
}

\author{
Pegah Yaghmaie and Andrea Schiffauerova \\ Concordia Institute for Information Systems Engineering, \\ Concordia University, Montreal, Canada \\ p yaghm@encs.concordia.ca andrea@encs.concordia.ca
}

\author{
Farideh Yaghmaei \\ School of Nursing and Midwifery, \\ Shahid Beheshti University of Medical Sciences, Tehran, Iran \\ farideh y2002@yahoo.com
}

\begin{abstract}
Over the recent years there has been a significant increase in the use of computer all over the world. One of the factors responsible for this rise is the general attitude of people toward computer. The aim of this study was to develop a scale for the assessment of the attitude toward computer in the Iranian context, and to validate the content and the face of this scale. Four-phase methodology which we used consisted in the initial identification of the pool of items, conducting and analyzing of the interviews and finally testing of the content and face validities. The results of the validity tests have shown that 33 items out of the initial selection of 60 items are valid. We conclude that the developed scale is valid for the use in the Iranian context. Furthermore, the scale is proposed for the use in both organizations and universities to evaluate the attitudes of the students or employees toward computer.
\end{abstract}

Keywords: attitude, computer, scale development, Iran

\section{Introduction}

Since computerized systems are increasingly becoming common in all work situations, end-user computing (EUC) has rapidly gained a great deal of attention in the management information systems (MIS) literature (Capron, 1990; Morgan,1995; Bullen, 1986). Computerized information systems or information technologies are important tools that can be used for a variety of purposes, such as solving problems (Lawlor, 1994), providing security of data (Goss et al.,1995), enabling accurate, fast and better decision making (Lawlor, 1994; Sheingold et al., 1987; Anderson et al., 1992), providing organized and fast information (Goss et al.,1995; Robey and Azevedo, 1994), facilitating wide communication (Brown, 1984; McAteer 1994; Bentley, 1995), reducing paperwork (Goss et al.,1995; Lawlor,1994), increasing users' satisfaction (Venkatesh and Morris,

Material published as part of this publication, either on-line or in print, is copyrighted by the Informing Science Institute. Permission to make digital or paper copy of part or all of these works for personal or classroom use is granted without fee provided that the copies are not made or distributed for profit or commercial advantage AND that copies 1) bear this notice in full and 2) give the full citation on the first page. It is permissible to abstract these works so long as credit is given. To copy in all other cases or to republish or to post on a server or to redistribute to lists requires specific permission and payment of a fee. Contact Publisher@InformingScience.org to request redistribution permission.
2000), improving ease of use and enhancing the usefulness of computerized systems (Amoroso and Gardner, 2004), and saving time (Robey and Azevedo, 1994). Computerized systems also enable managers to improve their performance and productivity (Igbaria et al.,1995), use their time more efficiently and solve problems more effectively than others (Nickerson, 1981). 
Nevertheless, even though there are so many advantages in using computerized systems, the attitudes toward computer can vary greatly among individuals. For many people, the computer will be a sign of progress and development, and represent increased performance and efficiency, but for others, it is depersonalization, loss of privacy and fear are associated with the growing use of computers (Hellman, 1976; Meier, 1985). Many possible attitudinal reactions to the increasing usage of computers are thus encountered throughout our society (Gutek et al., 1984; Kerber, 1983; Lee, 1970; Nickell and Seado, 1986; Schiller and Gilchrist,1971; Weinberg, 1985). It is assumed in this paper that these reactions vary based on the social, cultural, historical, political, religious and geographical context as well.

One of the many challenges in this research area is to develop tools and techniques for reliable and valid evaluation of people's attitudes towards computer technology. The effect of exposure to computer technology has received increasing attention among educators and scholars in recent years. Many researchers in 1980s and 1990s developed scales for measuring computer attitudes (Lee, 1970; Popovich et al.,1987; Quintanar et al., 1982; Reece and Gable, 1982; Loyd and Gressard, 1984, 1985; Oetting, 1983; Anderson et al., 1979; Bear et al., 1987; Soh, 1998; Gressard and Loyd, 1986; Hill et al.1987; Koohang, 1989; Lee, 1970; Mahmood and Medewitz, 1989; Massoud, 1990; Meier and Lambert, 1991; Nickell, 1987; Popovich et al., 1987; Rosen et al., 1987; Turnipseed and Bums, 1991; Woodrow, 1990; Wuand and Morgan, 1989). Some of these scales are widely used until today, but not much research in terms of developing new computer attitude scales has been done afterwards.

While the scales mentioned are useful, not many computer attitude scales have been developed and customized to the specific nationalities or populations. Capturing the specific beliefs and feelings within certain social and national context is therefore the objective of this paper. Since there are no such studies focused on Iran, this work is the first study which aims to develop a scale for the assessment of the attitude toward computer in the Iranian context, and to validate the content and the face of this scale. The paper is organized as follows: In the next section the first phase involving the identification of the pool of items from the previous studies will be described, and then the second phase brings the description and the analysis of the interviews, and the following two phases will test the content and face validities. The final section will conclude.

\section{The Development of the Iranian Computer Attitude Scale (ICAS)}

\section{Phase 1: Developing the Initial Pool of Items}

In the current study, in order to generate a representative sample of items associated with computer attitude, a variety of procedures were employed. The first was to review the literature that was related to experience, computer experience and its measurement. A pool of items was identified from previous surveys and relevant literature. The literature included articles and books that addressed the topic of computer attitude of users. The items selected from the literature had 'attitude' or 'computer attitude' as their keywords in the title, in the keyword list or as a user's characteristics.

\section{Phase 2: Conducting and Analysis of the Interviews}

In this phase, interviews were conducted and their results analyzed. In the current study, the aim of the interviews was to ascertain and measure the psychological effects of computer attitude on the participants' knowledge, feelings and practice. In other words, the purpose was to obtain the sample perception in relation to computer attitude. 
The face-to-face interviews were conducted with the participants. This method was helpful for the researcher and the participants could hear each other's opinions and views. In the current study, 20 participants were selected.

The data was collected by interviewing lecturers at universities who had computer experience in their particular area of work. Before each interview, the researcher explained to the participants the aim of the interview, the recording procedure of the interview and confidentiality of their personal details. Furthermore, the researcher provided confidentiality even for content analysis and the possible publication of the study's results.

The aim of data analysis is to uncover the meaning of the data (Minichiello et al., 1991). There are different methods which could be used, but the method we selected focused on content analysis and consequently, 'meaning units'. In other words, the text was broken into meaning units for developing a category system and gathering of ideas of similar meaning.

In the current study, the researcher transcribed all the interviews exactly. In preparing the interviews' transcriptions, a wide margin was left around the text. All the transcriptions were kept on an original disc and analyzing was undertaken from a copy of the transcriptions.

After the transcription, the researcher 'cleaned' the text. Thus, only that part of the text that was helpful and useful for analysis was left on the disc. Each part of meanings was separated by double space in order to ease the reading of the results. Therefore, the parts with different meaning were separated.

All the text was carefully worked over to uncover the exact meaning. The meaning unit can be one word or one or two sentences. Therefore, all the transcription was divided into meaning units. This stage required time and an experienced analyzer.

After dividing the text into meaning units, the data were categorized based on the same meaning so the researcher looked for similarities and differences.

For categorizing the transcriptions on the computer screen the following steps were taken by the researcher:

- Determination of the names of categories.

- Determination of one letter for describing each category.

- Selection and placement of the appropriate letter next to each of the units at the left side of the meaning units.

Units that were not relevant to the aim of the interview were classified as 'other categories'.

By determining all the text and sorting from the tools menu of WordPerfect, the researcher provided sorting for all the text based on the meaning units. Thus, automatically the alphabetical sorting ability of WordPerfect, arranged all the 'A', all the 'B', etc.

Finally, using the described approaches, i.e. the literature review and interviews, the Iranian Computer Attitude Scale" (ICAS) was developed with a 60 five-point Likert scale. Newly developed instruments should be tested, revised and retested several times to improve their psychometric properties. Researchers need to be confident in using an instrument. There are different types of validity. For the Iranian Computer Attitude Scale" (ICAS), two kinds of validity such as; content and face were measured. These are described in the following two sections.

\section{Phase 3: Testing the Content Validity}

Nunnally (1978), argues that there are two standards for ensuring content validity: firstly, the sampling of the items and secondly, the method of constructing the test. Thus, for content validity two judgments are necessary; the extent of each item for defining the traits and the set of items 
that represent all aspects of the trait. Therefore, content validity measures the comprehensiveness and representativeness of the content of a scale. Usually this type of validity is considered by researchers because it can help to ensure construct validity.

This stage involves Content Validity Index (CVI) based on (Waltz \& Bausell, 1983; Yaghmaie, 2003, 2007, 2009; Loiselle et al., 2011) and face validity of the ICAS that was based on computer experts' judgment (Waltz \& Bausell, 1983; Yaghmaie, 2003, 2007, 2009; Loiselle et al., 2011).

To test the content validity of the ICAS, the researcher selected 19 experts among the lectures and students at universities. The participants had computer experience in their work, which they gained either as computer users or teachers. The researcher gave a copy of the ICAS and explained the purpose and objectives of the study to each of them individually. The experts were then asked to rate each item based on relevance, clarity, simplicity and ambiguity on a four-point scale.

According to CVI, the relevance of each item to a particular objective was rated by 19 experts using the four-point scale. Items that had CVI over 0.75 were kept and the next were discarded.

To determine the clarity, simplicity and ambiguity of each item, the total score in each category (clarity, simplicity and ambiguity) that was marked by the experts, was the best available indicator which was used to determine whether to add, modify or delete some words from each items. Therefore, the remaining items were modified, based on the experts' opinions. Discarding those items of the scale that were not related to the domain of computer experience led to the decrease in the number of items from 60 to 33.

\section{Phase 4: Testing the Face Validity}

Face validity refers to the subjective judgment of respondents, which can determine the formulation of the tool that has been designed. To test the face validity of the ICAS, the researcher distributed copies of the questionnaire to 20 individuals and asked them to check the punctuation, mark ambiguous items, give comments about the questions and add any suggestions that could improve the tool. On the basis of the feedback, the researcher modified the formulation of some items.

\section{Conclusions}

With respect to the increase of computer usage, this work highlights the importance of the evaluation of the human attitude toward computer. It is suggested that the employees' attitudes toward computer in organizations and the students' attitudes at universities as well should be regularly assessed to gain further insights into the existence of both positive and negative attitudinal reactions toward the increased use of the computers.

This study presents the development of a valid measure of users' computer attitude in Iran which is developed based on the Iranian culture. The "Iranian Computer Attitude Scale" with 33 items has been developed and the results have showed that the scale is valid. Further research, especially aimed at further clarification of the underlying constructs and assuring the reliability of the scale, would increase the tool's generalize ability.

\section{References}

Amoroso, L. D., \& Gardner, C. H. (2004). Development of an instrument to measure the acceptance of internet technology by consumers. IEEE, Proceedings of the 37th Annual Hawaii International Conference on System Sciences (HICSS'04). Retrieved from http://csdl.computer.org/comp/proceedings/hicss/2004/2056/08/205680260cabs.htm 
Anderson, R. A., Dobal, M. T., \& Blessing, B. B. (1992). Theory-based approach to computer skill development in nursing administration. Computers in Nursing, 10(4), 152-157.

Anderson, R. E., Hansen, T. P., Johnson, D. C., \& Klassen, D. L. (1979). Minnesota computer literacy awareness assessment (Tech. Rep.). St. Paul: St. Paul Minnesota Educational Computing Consortium.

Bear, G. G., Richards, H. C., \& Lancaster, P. (1987). Attitudes toward computers: Validation of a computer attitudes scale. Journal of Educational Computing Research, 3, 207-218.

Bentley, T. (1995). Humane information management. Management Accounting, 73(3), 65-65.

Brown, V. T. (1984). Survey of user satisfaction: Nursing's attitude toward MIS. IEEE, 601-604.

Bullen, C. V. (1986). Company experience with end-user computing. In M. Jark (Ed), Managers, micros and mainframes integrating system for end-users (pp. 73-85.). New York: John Wiley and Sons.

Capron, H. L. (1990). Computers tools for an information age (2nd ed.). California: The Benjamin Cummings Publishing Company.

Goss, E. P., Buelow, V., \& Ramchandani, H. (1995). The real impact of a point-of-care computer system on ICU nurses. Journal of Systems Management, 43-47.

Gressard, C., \& Loyd, B. H. (1986). Validation studies of a new computer attitude scale. AEDS, 2, 295-301.

Gutek, B. A., Bikson, T. K., \& Mankin, D. (1984). Individual and organizational consequences of computer-based office information technology. In S. Oskamp (Ed.), Applied social psychology annual (vol. 5). Beverly Hills: Sage.

Hellman, H. (1976). Technophobia: Getting out of the technology trap. New York: Evans.

Hill, T., Smith, N. D., \& Mann, M. (1987). Role of efficacy expectations in predicting the decision to use advanced technologies: The case of computers. Journal of Applied Psychology, 72, 307-313.

Igbaria, M., Iivari, J., \& Maragahh, H. (1995). Why do individual use computer technology? A Finnish case study. Information and Management, 29(5), 227-238.

Kerber, K. W. (1983). Attitudes towards specific uses of the computer: Quantitative decision making and record-keeping applications. Behaviour and Information Technology, 2, 197-209.

Koohang, A. A. (1989). A study of attitudes toward computers: Anxiety, confidence, liking, and perception of usefulness. Journal of Research on Computing in Education, 22, 137-150.

Lawlor, S. C. (1994). Computer information systems (3rd ed.). Philadelphia: The Dryden press, Harcourt Brace College Publishers.

Lee, R. S. (1970). Social attitudes and the computer revolution. Public Opinion Quarterly, 34, 53-59.

Loiselle, C. G., McGrath, J. P., Polit, D. F., \& Beck, C. T. (2011). Canadian essentials of nursing research (3rd ed.). Philadelphia: Wolters Kluwer Healths.

Loyd, B. H., \& Gressard, C. (1984). Reliability and factorial validity of computer attitude scales. Educational and Psychological Measurement, 44, 501-505.

Loyd, B. H., \& Gressard, C. (1985). The reliability and validity of an instrument for the assessment of computer attitudes. Educational and Psychological Measurement, 45, 903-908.

Mahmood, M. A., \& Medewitz, J. N. (1989). Assessing the effect of computer literacy on subjects' attitudes, values, and opinions toward information technology: An exploratory longitudinal investigation using the linear structural relations (LISREL) model. Journal of Computer-Based Instruction, 16(1), 20-28.

Maltby, J., Williams, G. A., McGarry, J., \& Day, L (2010). Research methods for nursing and healthcare. Edinburgh, UK: Pearson Education Limited.

Massoud, S. L. (1990). Factor validity of a computer attitude scale. Journal of Research on Computing in Education, 22(3), 290-299. 
McAteer, P. F. (1994). Harnessing the power of technology. Training and Development, 48(8), 64-68.

Meier, S. T. (1985). Computer aversion. Computers in Human Behavior, 1, 171-179.

Meier, S. T., \& Lambert, M. E. (1991). Psychometric properties and correlates of three computer aversion scales. Behavior Research Methods, Instruments, \& Computers, 23(1), 9-15.

Minichiello, V., Aroni, R., Timewell, E., \& Alexander, L. (1991). In-depth interview. Melbourne: Longman Cheshire Pty Limited, Longman House.

Morgan, G. G. (1995). ITEM: A strategic approach to information systems in voluntary organisations. Journal of Strategic Systems, 4(3), 225-237.

Nickell, G. S. (1987). The computer attitude scale. Computers in Human Development, 2, 301-306.

Nickell, G. S., \& Seado, P. C. (1986). The impact of attitudes and experience on small business computer use. American Journal of Small Business, 10, 37-48.

Nickerson, R. S. (1981). Why interactive computer systems are sometimes not used by people who might benefit from them. International Journal of Man-Machine Studies, 15, 469-483.

Nunnally, J. C. (1978). Psychometric theory (2nd ed.). New York: McGraw-Hill.

Oetting, E. R. (1983). Manual for Oetting's Computer Anxiety Scale (C034PAS). Fort Collins, CO: Rocky Mountain Behavioral Science Institute.

Popovich, P. M., Hyde, L. R., \& Zakrajsek, T. (1987). The development of the attitudes toward computer scale. Educational and Psychological Measurement, 47, 261-269.

Quintanar, L. R., Crowell, C. R., \& Pryor, J. B. (1982). Human computer interaction: A preliminary social psychology analysis. Behavior Research Methods and Instrumentation, 14, 210-220.

Reece, M., \& Gable, R. (1982). The development and validation of a measure of general attitudes towards computers. Educational and Psyychological Measurement, 42, 913-916.

Robey, D., \& Azevedo, A. (1994). Cultural analysis of the organisational consequences of information technology. Accounting Management and Information Technology, 4(1), 23-37.

Rosen, L. D., Sears, D. C., \& Weil, M. M. (1987). Computerphobia. Behavior Research Methods, Instruments, \& Computers, 19(2), 167-179.

Schiller, C., \& Gilchrist, B. (1971). A national survey of the public' attitudes toward computers. New York: Time Magazine and the American Federation of Information Processing Societies.

Sheingold, K., Martin, L. M. W., \& Endreweit, M. E. (1987). Preparing urban teachers for the technological future. In R. D. Pea \& K. Sheingold (Eds), Mirrors of minds: Patterns of experience in educational computing (pp. 67-85). USA: Ablex Publishing Corporation.

Soh, K. C. (1998). Cross cultural validity of Selwyn Computer Attitude Scale. Unpublished manuscript

Turnipseed, B. L., \& Bums, O. M. (1991). Contemporary attitudes toward computers: An exploration of behavior. Journal of Research on Computing in Education, 23, 611-625.

Venkatesh, V., \& Morris, M. G. (2000). Why don't men ever stop to ask for directions? Gender, social influence, and their role in technology acceptance to use behavior. MIS Quarterly, 24, 115-139.

Waltz, C. F., \& Bausell, R. B. (1983). Nursing research: Design, statistics and computer analysis (2nd ed.). Philadelphia: F. A. Davis Company.

Weinberg, S. (1985). Computer phobia. New York: Banbury Books.

Woodrow, J. E. J. (1990). Locus of control and student teacher computer attitudes. Computer and Education, $14,421-432$.

Wu, Y. K., \& Morgan, M. (1989). Computer use, computer attitudes, and gender: Differential implications of micro and mainframe usage among college students. Journal of Research on Computing in Education, 22, 229-240. 
Yaghmaie, F. (2003). Content validity and its estimation. Journal of Medical Education, 3(1) 25-28.

Yaghmaie, F. (2007). Measuring behavior in research by valid and reliable instruments (1st ed.). Tehran: Shahid Beheshti University of Medical Sciences \& Health Services.

Yaghmaie, F. (2009). Measuring behavior in research by valid and reliable instruments (2nd ed.). Tehran: Shahid Beheshti University of Medical Sciences \& Health Services, Golban.

\section{Biographies}

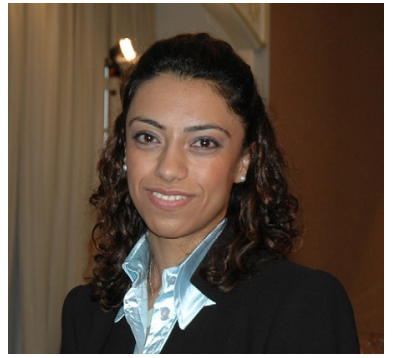

Pegah Yaghmaie is currently a student of Master of Applied Science in Quality System Engineering at Concordia University, Canada. A holder of bachelor degree in computer software engineering, she received her Master of International Business from University of Wollongong in UAE. Her experience in industrial sector includes web designing and business development in sales and marketing. During her education and work experience she traveled and lived in various countries, which not only broadened her vision, but it also enabled her to integrate cross-cultural aspects into her research. Pegah's thesis is focused on evaluation of firms' behavior in collaboration network and their performance.

Andrea Schiffauerova has obtained Ph.D. and M.Eng. degrees in industrial engineering from

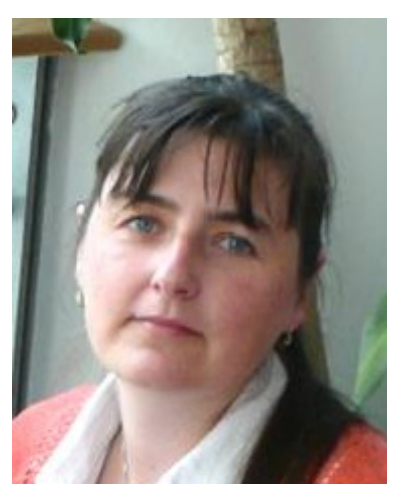

École Polytechnique de Montréal, Canada, and a bachelor degree in economic engineering from Silesian University, Czech Republic. Currently she is an assistant professor at Concordia Institute for Information Systems Engineering at Concordia University, Canada. Her area of expertise encompasses economics of innovation and science, management of knowledge and technology, and engineering management. She is very interested in designing effective and sustainable innovation systems, particularly in studying innovation networks and knowledge diffusion. Her other research areas cover topics of new product development, which are concerned with quality, engineering change management, process management and design effectiveness.

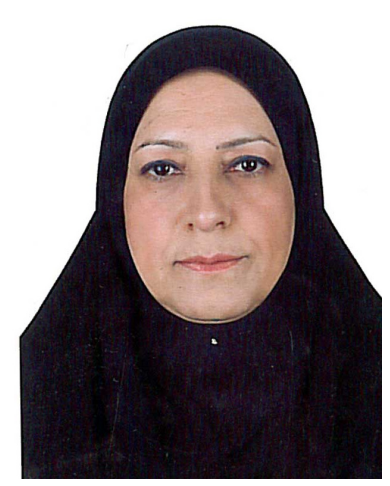

Farideh Yaghmaie is an associate professor in Shahid Beheshti University of Medical Sciences in Tehran, Iran. She received her PhD in public health from University of Wollongong in Australia. Through her 30 years of experience in academic areas, she has published over 50 articles in both Farsi and English languages in various medical and research journals, books and book chapters. She is also reviewer of many Iranian and English Journals such as; International Journal of Nursing and Midwiferyy (IJNM), Educational Researchand Journal of Research in International Business and Management. During past years she has concentrated on development scales, questionnaires and forms. 